Tropical Journal of Pharmaceutical Research June 2010; 9 (3): 231-236

(C) Pharmacotherapy Group, Faculty of Pharmacy, University of Benin,

Benin City, 300001 Nigeria.

All rights reserved.

Research Article

Available online at http://www.tjpr.org

\title{
Isolation and Morphological Characterization of Antibiotic Producing Actinomycetes
}

\author{
Nanjwade Basavaraj $\mathbf{K}^{1 *}$, $\mathbf{S}$ Chandrashekhara ${ }^{2}$, Ali $\mathbf{M}$ \\ Shamarez ${ }^{1}$, Prakash S Goudanavar ${ }^{2}$ and Fakirappa V Manvi ${ }^{1}$ \\ ${ }^{1}$ KLES's College of Pharmaceutical Sciences, K.L.E. University, Nehru Nagar, Belgaum, Karnataka, ${ }^{2}$ KLES's College \\ of Pharmaceutical Sciences, Nipani, Karnataka, India,
}

\begin{abstract}
Purpose: To isolate and characterize antibiotic producing actinomycetes from soil samples in Belgaum, Karnataka, India.

Methods: Crowded plate technique was used for the isolation of actinomycetes in media such as soybean - casein digest medium and actinomycetes isolation agar. The morphological and cultural characterization of one of the selected strains, designated A-4, was performed as per International Streptomycete Project (ISP).

Results: Morphological and cultural studies showed that A-4 belonged to the Actinomycete genus. The morphological and cultural characteristics of the A-4 mutant showed cellular and aerial growth as well as soluble pigment formation in various ISP media.

Conclusion: Findings from this investigation revealed that the selected strain, $A-4$, is an actinomycete.
\end{abstract}

Keywords: Actinomycete, Antibiotic, MIC, Crowded plate technique, Morphology. 


\section{INTRODUCTION}

Antibiotics are the best known products of actinomycete. Over 5,000 antibiotics have been identified from the cultures of Grampositive and Gram-negative organisms, and filamentous fungi, but only about 100 antibiotics have been commercially used to treat human, animal and plant diseases. The genus, Streptomycete, is responsible for the formation of more than $60 \%$ of known antibiotics while a further $15 \%$ are made by a number of related Actinomycetes, Micromonospora, Actinomadura, Streptoverticillium and Thermoactinomycetes [1]. Antibiotics, because of their industrial importance, are the best known products of actinomycetes. The actinomycetes produce an enormous variety of bioactive molecules, e.g., antimicrobial compounds. One of the first antibiotics used is streptomycin produced by Streptomycin griseus.

On the whole, the last 55 years have seen the discovery of more than 12,000 antibiotics. The actinomycetes yielded about $70 \%$ of these, and the remaining $30 \%$ are products of filamentous fungi and non-actinomycete bacteria. Most of the bioactive compounds from actinomycete sort into several major structural classes such as amino glycosides (e.g., streptomycin and kanamycin), ansamycins (e.g., rifampin), anthracyclines (e.g., doxorubicin), $\beta$-lactam (cephalosporins), macrolides (e.g., erythromycin), and tetracycline. [2]

The present study is aimed at isolating an antibiotic capable of acting on clinically resistant strains of infectious organisms.

\section{EXPERIMENTAL}

\section{Materials}

Dextrose IP, sodium chloride ( $\mathrm{NaCl})$, soyabean meal, n-butanol, silicon oil, dimethyl sulphoxide (DMSO), n-hexane, tryptone, lactose, maltose, fructose, yeast extract powder, nutrient agar, agar powder,
International Streptomycetes Project (ISP) 2 to 7 media, actinomycetes agar, Bennett's agar, nutrient broth, sucrose, silica gel 60120 mesh, silica gel powder, chloroform, ethyl acetate, starch, magnesium sulphate, potassium dihydrogen phosphate, methanol, silica gel TLC grade, peptone, skimmed milk and glucose were all of analytical or pharmacopoeial grade and were obtained from commercial suppliers. They were used as received without further purification.

\section{Isolation of antibiotic producing soil isolates}

\section{Collection of soil samples}

The soil samples were collected from various locations in and around Belgaum, Karnataka, India, dried separately at $45^{\circ} \mathrm{C}$ for $1 \mathrm{~h}$ in a hot air oven and then cooled to room temperature. The soil sample $(1 \mathrm{~g})$ was added to a conical flask containing $100 \mathrm{ml}$ of sterile water and few drops of Tween 80. The flasks were shaken for $30 \mathrm{~min}$ in an orbital shaker incubator at $27^{\circ} \mathrm{C}$ and their contents designated stock cultures $[3,4]$

\section{Screening of soil samples by crowded plate technique}

A series of culture tubes containing $9 \mathrm{ml}$ of sterile water was taken. From the stock culture, $1 \mathrm{ml}$ suspension was transferred aseptically to the $1^{\text {st }}$ tube $\left(10^{-1}\right)$ and mixed well. Further serial dilutions were made to produce $10^{-5}$ suspensions were made. Suspension $(0.1 \mathrm{ml})$ from each culture tube was spread on sterile soyabean-casein digest medium (SBCD) plates, actinomycetes isolation agar (AIA) medium plates and starch-casein agar medium plates aseptically in a laminar-air flow cabinet. The plates were incubated at $27 \pm 2{ }^{\circ} \mathrm{C}$ for $84 \mathrm{~h}$. The plates were observed intermittently during incubation.

After 72 h, whitish pin-point colonies, characteristic of actinomycetes and with a clear zone of inhibition around them were 
seen. The pinpoint colonies with inhibitory or clear zone of inhibition were selected and purified into actinomycetes agar slants. The selected strains were further purified by multiple streaking method. The stock cultures of each selected strain was prepared and maintained in actinomycete agar slants at +4 ${ }^{\circ} \mathrm{C}$ [3,5-7]. The actinomycete colonies isolated from the crowded plate were selected for the further studies and labelled A1, A2, .......A9.

\section{Preliminary screening of crude antibiotic}

\section{Agar streak method}

The microbial sensitivity of the soil isolates was analyzed by agar streak method. Each of the isolate was streaked as a straight line on SBCD medium and incubated at $27^{\circ} \mathrm{C}$ for 6 days (144 h). After the 6th day, different strains of microorganisms were streaked at right angle, but not touching each other, and then incubated at $37^{\circ} \mathrm{C}$ for $24 \mathrm{~h}$ in the case of bacteria and $27^{\circ} \mathrm{C}$ for $48 \mathrm{~h}$ in the case of fungi. If the organism is susceptible to the antibiotic produced by actinomycetes, then it will not grow near the actinomycetes. The zone of inhibition against each test organism was noted. The isolated actinomycetes were screened against some microorganisms Bacillus subtilis, Staphylococcus aureus, Escherichia coli, Pseudomonas aeruginosa, Aspergillus niger and Candida albicans [8]. Based on their antimicrobial properties, isolates were chosen for the further biochemical characterization.

\section{Morphological and cultural characteri- zation}

Morphological and cultural characters of the selected actinomycetes strains were studied by inoculating the selected strain into sterile ISP media. The media were sterilized and poured into sterile Petri dish. After solidification of the media, the culture of the selected strain was streaked on the media surface aseptically and incubated at $27^{\circ} \mathrm{C}$ for 7 days. Morphological properties such as colony characteristics, type of areal hyphae, growth of vegetative hyphae, fragmentation pattern and spore formation were observed $[4,9]$.

\section{Microscopical characterization Gram staining method}

A smear of the selected strain (A-4) was prepared on a clean glass slide and the smear was allowed to air-dry and then heatfixed. The heat-fixed smear was flooded with crystal violet and after one minute, it was washed with water and flooded with mordant Gram's iodine. The smear was decolorized with $95 \%$ ethyl alcohol, washed with water and then counter-stained with safranin for 45 s. After washing with water, the smear was dried with tissue paper and examined under oil immersion $(100 \mathrm{x})$ [10].

\section{RESULTS}

\section{Soil screening}

Nine actinomycetes were isolated from the soil samples. They had pinpoint colonies with zone of inhibition. The presence of relatively large populations of actinomycetes in the soil samples of Belgaum indicates that the source is an eminently suitable ecosystem. Pertinent details of the soil samples and the actinomycetes are shown in Table 1.

\section{Microbial sensitivity}

Out of the nine isolated actinomycetes screened for antimicrobial activity against five bacterial and three fungal strains by agar streak method, six, namely, A1, A2, A3, A4, $A 5$ and $A 6$ showed significant antimicrobial activity against both Gram-positive and Gram-negative organisms. However, A4 showed a very broad spectrum with the highest scores (Table 2). 
Table 1: Characteristics of soil samples and number of actinomycetes isolated

\begin{tabular}{|c|c|c|c|c|c|c|}
\hline \multirow{2}{*}{$\begin{array}{l}\text { Dilution } \\
\text { of soil } \\
\text { samples }\end{array}$} & \multirow[t]{2}{*}{$\begin{array}{l}\text { Heat treatment } \\
\left(45^{\circ} \mathrm{C}, 1 \mathrm{~h}\right)\end{array}$} & \multicolumn{3}{|c|}{$\begin{array}{l}\text { No. of actinomycetes colonies } \\
\text { on isolation media }\end{array}$} & \multirow[t]{2}{*}{$\begin{array}{l}\text { Nature of soil } \\
\text { sample }\end{array}$} & \multirow[t]{2}{*}{ Soil pH } \\
\hline & & SBCD & AIA & SCA & & \\
\hline $10^{-4}$ & NA & -- & -- & -- & Water logged & 7.5 \\
\hline $10^{-4}$ & NA & -- & -- & -- & mud & 7.5 \\
\hline $10^{-3}$ & AP & 4 & 6 & -- & Water logged & 6.3 \\
\hline $10^{-4}$ & AP & 1 & 3 & -- & mud & 7.0 \\
\hline $10^{-3}$ & AP & -- & -- & -- & Loamy & 8.0 \\
\hline $10^{-3}$ & AP & -- & -- & -- & Sandy & 7.8 \\
\hline $10^{-4}$ & AP & 17 & 38 & 15 & Mud & 5.3 \\
\hline $10^{-5}$ & AP & 33 & 48 & 36 & Mud & 5.7 \\
\hline $10^{-5}$ & AP & 48 & 50 & 32 & Red-dry soil & 5.4 \\
\hline
\end{tabular}

Note: $N A=$ heat not applied; $A P=$ heat applied; $S B C D=$ soyabean casein digest medium; $A I A=$ actinomycetes isolation agar; SCA = starch casein agar, Dilution of soil samples was done by two-fold serial dilution technique.

Table 2: Sensitivity of various microorganisms to the soil isolates

\begin{tabular}{ccccccccc}
\hline $\begin{array}{c}\text { Soil } \\
\text { isolate }\end{array}$ & $\begin{array}{c}\text { B. } \\
\text { subtilis }\end{array}$ & $\begin{array}{c}\text { S. } \\
\text { aureus }\end{array}$ & $\begin{array}{c}\boldsymbol{E} . \\
\text { coli }\end{array}$ & $\begin{array}{c}\boldsymbol{K} . \\
\text { pneumoniae }\end{array}$ & $\begin{array}{c}\boldsymbol{P} . \\
\text { aeruginosa }\end{array}$ & $\begin{array}{c}\boldsymbol{A} . \\
\text { niger }\end{array}$ & $\begin{array}{c}\boldsymbol{A} . \\
\text { terreus }\end{array}$ & $\begin{array}{c}\boldsymbol{C} . \\
\text { albicans }\end{array}$ \\
\hline A1 & ++ & + & + & - & + & - & - & + \\
A2 & + & ++ & + & - & ++ & - & - & + \\
A3 & - & - & ++ & - & ++ & - & + & ++ \\
A4 & ++ & ++ & +++ & ++ & + & + & - & ++ \\
A5 & + & - & + & + & + & - & - & - \\
A6 & + & - & + & - & - & - & - & - \\
A7 & ++ & - & + & + & + & + & - & + \\
A8 & - & + & + & + & - & + & + & - \\
A9 & - & + & - & + & - & - & - & -
\end{tabular}

$+++=$ Very good inhibition, $++=$ Good inhibition

$+=$ Moderate inhibition, $\quad-=$ No inhibition

\section{Morphological and cultural characteristics of strain A4}

The morphology of strain A4 in different ISP media showed filamentous growth in ISP-5 and ISP-7 media, while pigmentation was seen in ISP-6 medium. Microscopical observation (x 10 and x 100 magnification) after Gram-staining revealed that A4 is a Gram-positive and rod-shaped microorganism. Other morphological characteristics such as colony features, type of areal hyphae, growth of vegetative hyphae, fragmentation pattern and spore formation are detailed in Table 3 . They indicate that strain A4 belongs to the genus, Actinomycetes.

\section{DISCUSSION}

In the course of screening for novel antimicrobial substances (antibiotics) from soil samples, antibiotic-producing actionmycete cultures were recorded from soil samples taken in Belgaum, Karnataka, India. As stated earlier, actinomycetes have provided many important bioactive compounds of high commercial value and continue to be routinely screened for new bioactive substances. 
Table 3: Morphological and cultural characteristics of the strain A-4

\begin{tabular}{|c|c|}
\hline Medium used & Characteristics of strain A4 \\
\hline Tryptone-yeast extract broth (TSP-1) & Growth occurred by pellicle formation. \\
\hline ISP-2 & $\begin{array}{l}\text { Creamish white-coloured colonies with a clear zone } \\
\text { around them }\end{array}$ \\
\hline (Oatmeal agar) ISP-3 & $\begin{array}{l}\text { Slightly black-creamish colour, thick colonies with } \\
\text { no aerial mycelium formation. }\end{array}$ \\
\hline Inorganic salt-starch agar (ISP-4) & $\begin{array}{l}\text { Blackish-brown coloured thick colonies with waxy } \\
\text { margin and convex surface. }\end{array}$ \\
\hline $\begin{array}{l}\text { Glycerol asparagines agar base } \\
\text { (ISP-5) }\end{array}$ & $\begin{array}{l}\text { Whitish coloured thin colonies with striated surface } \\
\text { and less aerial mycelium and filamentous growth. }\end{array}$ \\
\hline $\begin{array}{l}\text { Peptone yeast extract iron agar } \\
\text { (ISP-6) }\end{array}$ & $\begin{array}{l}\text { Thin, transparent colonies with black coloured } \\
\text { soluble pigments. No filamentous growth. }\end{array}$ \\
\hline Tyrosine agar base (ISP-7) & $\begin{array}{l}\text { Cream coloured, lobe-shape, convex surface, and } \\
\text { little mycelium growth. }\end{array}$ \\
\hline Carbon utilization agar (ISP-9) & $\begin{array}{l}\text { Thin, yellowish golden-coloured colonies with little } \\
\text { mycelium growth. }\end{array}$ \\
\hline
\end{tabular}

In the present study, nine actinomycetes were isolated from soil samples with the aid of isolation media - soyabean-casein digest medium (SBCD), actinomycetes isolation agar (AIA) and starch-casein agar, having pinpoint colonies with zone of inhibition, cultured by crowded plate technique. Addition of $\mathrm{CaCO}_{3}$ and heat treatment aids the development of actinomycetes populations in the soil [3-7]. The presence of relatively large populations of actinomycetes in the soil samples of Belgaum indicates that it is a suitable ecosystem that promotes the isolation of actinomycetes during screening programmes.

It can be deduced from the results that the number of actinomycetes generally decreased with heavy rainfall which increases greatly the moisture content of soil. Furthermore, the growth of actinomycetes was favoured by neutral or slightly alkaline conditions. The fact that actinomycetes number was lower on the soil surface than $11-15 \mathrm{~cm}$ deep down into the soil may be attributed to the favourable combination of suitable $\mathrm{pH}$ and water content. The number of actinomycetes in black-alkaline sandy soil was very high.

\section{CONCLUSION}

Findings from morphological, cultural and microscopical studies reveal that the isolated and investigated strain designated as A4 is an actinomycete.

\section{REFERENCES}

1 Waksman SA. The Actinomycetes. $1^{\text {st }}$ edition, Watham, MASS, USA, 1954; pp 185-191.

2 Brun YV, Skimkets LJ. Prokaryotic development. ASM Press, 2000; pp 11-31.

3 Casida LE. Industrial Microbiology, $3^{\text {rd }}$ edition. Wiley Easter Ltd., 1984; pp 3-437.

4 Haque SFK, Sen SK, and Pal SC. Screening and identification of antibiotic producing strains of Streptomyces. Hindustan Antibiot Bull 1992; (3-4): 76-83.

5. Hayakawa $M$, Momose $Y$, Kajiura $T$, Younazaki $T$, Tamura $T$, Hatano $K$, and Nonomura $H$. A selective isolation method for Actinomadura viridis in soils. J. Ferment. Bioeng. 1995; 79(3): 287-289.

6. Hayakawa $M$, Tamura $T$, Lino $H$, Nonomura $H$. Pollen-baiting and drying method for the highly selective isolation of Actinoplanes spp. from soil J. Ferment. Bioeng 1991;72(6): 433-438.

7. Augustine SK, Bhavsar SP, Baserisaleni $M$, Kapadnis BP. Isolation, Characterization and optimization of antifungal activity of an actinomycete of soil Origin. Indian J Exp Biol. 2004; 42: 928-932. 
Nanjwade et al

8. Haque SK, Sen SK, Pal SC. Antimicrobial spectra and toxicity of antibiotics From Streptomyces antibioticus sr 15-4. Indian J. Microbiol. 1996; 36: 113-114.

9. Yang $W u R$, Ho Chen $M$. Identification of the Streptomyces strain KS3- 5. Bot Bull Acad Sin 1995; 36: 201-205
10. Williams ST, Locci $R$, Beswick A, Kurtboke DI, Kuznetsov VD, Lemonnior FJ, Long PF. Detection and identification of novel actinomycetes. Res Microbiol 1993; 144(8): 653-656. 